\title{
POSS-Appended Diphenylalanine: Self-Cleaning, Pollution- Protective, and Fire-Retardant Hybrid Molecular Material
}

\author{
Krishnendu Maji and Debasish Haldar*(i) \\ Department of Chemical Sciences, Indian Institute of Science Education and Research Kolkata, Mohanpur 741246, West Bengal, \\ India
}

Supporting Information

\begin{abstract}
Ordered self-assemblies of hybrid molecules have potential as protective umbrellas against environmental pollution and corrosion. This article describes the design and fabrication of a new self-cleaning hybrid molecular material containing polyhedral oligomeric silsesquioxane (POSS) and diphenylalanine as hydrophobic and pollution-protective coating. The colorless organic-inorganic hybrid materials, in which the diphenylalanine motif controls the self-assembly, exhibit unique water resistance property and enhance mechanical strength of paper 1.5-fold. The hybrid building blocks self-assemble in antiparallel sheet manner through noncovalent interactions to form a supramolecular layerlike surface with enhanced roughness. The hybrid material is
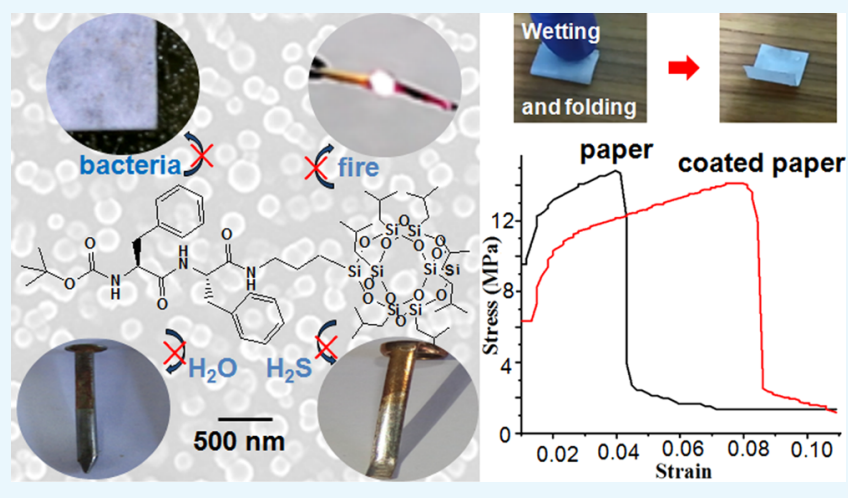
soluble in organic solvents at room temperature that makes it easy to coat on paper, wood, or metal surfaces. The coating is effective against rusting, corrosion, environmental pollution, and bacterial attack. The coating has been used as fire retardant and enhances fire safety. The sustainable molecular material is promising for the packaging industry and metal industry and artifact preservation.
\end{abstract}

\section{INTRODUCTION}

Organic-inorganic hybrid materials ${ }^{1}$ have recently attracted interest for their potential applications and high performance in molecular machines, ${ }^{2}$ sensors, ${ }^{3}$ catalysts, ${ }^{4}$ energy and optoelectronic devices. ${ }^{5}$ These hybrid materials exhibit both the properties of organic and inorganic materials and even novel characteristics that are not found in the parent compounds. Polyhedral oligomeric silsesquioxanes (POSS) are organicinorganic hybrid materials with the formula $\left(\mathrm{RSiO}_{1.5}\right)_{n}(n=6$, $8,10,12)$ and have nanometer-sized inorganic cores surrounded by organic functional groups. ${ }^{6-11}$ A POSS molecule with a unique cubic cagelike nanostructure has novel properties like high thermal and mechanical stability, flame retardancy, and low dielectric constant. ${ }^{12-14}$ POSS-based materials have a wide range of applications, including opticals, ${ }^{15}$ electronics, ${ }^{16}$ antimicrobial agents, ${ }^{17}$ and catalysis. ${ }^{18-22}$ Coughlin et al. have reported on the crystal structure and morphology of POSS nanoparticles. ${ }^{23}$ De and co-workers have reported on a polymer matrix incorporating the POSS-peptide conjugate. ${ }^{24} \mathrm{Xu}$ et al. have synthesized tetraphenylethene-modified POSS. ${ }^{25}$ However, the peptide-POSS hybrid for tuning the structural and functional properties and sustainability is rare. ${ }^{26}$

By precisely organizing the simple molecular building blocks by noncovalent interactions, nature has achieved complex materials with diverse structures and functions. Peptide motifs have structural and functional versatilities to form diverse supramolecular nanostructures. ${ }^{27-30}$ The peptides, like diphe- nylalanine, have been used to fabricate supramolecular materials, with significant physical and chemical stability ${ }^{31}$ and unique mechanical, ${ }^{32}$ electrical, $^{33,34}$ and optical ${ }^{35-37}$ properties. Gazit et al. have used the diphenylalanine nanotube as a template to cast silver nanowire. ${ }^{38}$ Herein, we have synthesized a hybrid molecule containing L-phenylalanine and POSS (Figure 1). Our goal was to couple diphenylalanine and POSS to fabricate a green and sustainable organic-inorganic hybrid material and create a self-assembled engineered structure of POSS and develop user-friendly coating material with stability, hardness, and thermo compatibility. In this context, the folding and interactions of the hydrophobic groups will be interesting.

\section{RESULTS AND DISCUSSION}

The target compound was synthesized by conventional solution-phase methods and purified and well characterized by ${ }^{1} \mathrm{H}$ NMR, ${ }^{13} \mathrm{C} \mathrm{NMR},{ }^{29} \mathrm{Si}$ NMR, Fourier transform infrared (FT-IR), and mass spectrometry (MS) analysis. A detailed description of the synthesis and characterization of hybrid compound $\mathbf{1}$ is given in the Supporting Information. Briefly, tBoc-protected diphenylalanine $\mathbf{2}$ was coupled with POSS amine 3 using a standard coupling reagent dicyclohexyl

Received: February 28, 2017

Accepted: April 28, 2017

Published: May 9, 2017 


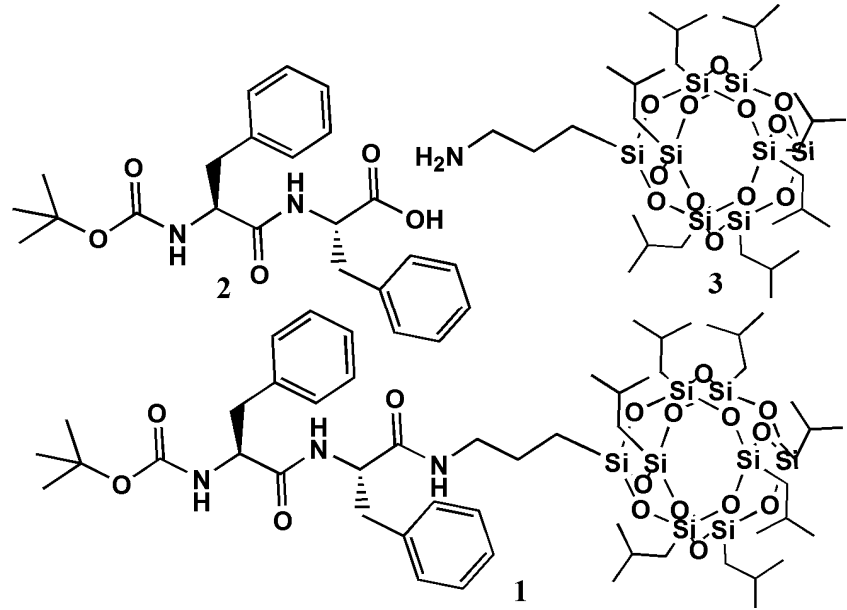

Figure 1. Chemical structures of compounds 1, 2, and 3.

carbodiimide (DCC) to obtain $\mathbf{1}$ in good yield. The signals at $\delta$ values of 7.28 and 7.05 in its ${ }^{1} \mathrm{H}$ NMR spectrum are assigned to the aromatic protons of diphenylalanine. The signals at $\delta 3.05$, 2.80, and 1.85 in its ${ }^{1} \mathrm{H}$ NMR spectrum are assigned to $\mathrm{C}^{\alpha} \mathrm{H}$, $\mathrm{C}^{\gamma} \mathrm{H}$, and $\mathrm{C}^{\beta} \mathrm{H}$ of POSS, respectively, suggesting that the diphenylalanine group was connected to the POSS moiety. The signals at $\delta$ values of -68.52 and -68.74 in the ${ }^{29} \mathrm{Si}$ NMR (99 $\mathrm{MHz}, \mathrm{CDCl}_{3}$ ) spectrum and the signal at $\mathrm{m} / z 1291.51$ in the ESI-mass spectra further confirmed the formation of POSSappended diphenylalanine.

The presence of both nonpolar and polar functionalities in $\mathbf{1}$ increases solubility in a wide range of organic solvents, with diverse polarity indexes, and allows for self-association. Initially, the self-assembly of the hybrid peptide $\mathbf{1}$ has been studied using different spectroscopic techniques. The POSS-containing peptide 1 in DCM solution exhibits absorption bands at 228 , 259 , and $288 \mathrm{~nm}$ due to the characteristic $\mathrm{n}-\pi^{*}$ and $\pi-\pi^{*}$ transitions. The intensity of the band increases with the gradual increase in the concentration of peptide 1 (Figure S1 of the Supporting Information). The emission spectrum of peptide 1 in DCM solution shows that with increasing concentration the band at $365 \mathrm{~nm}$ for the aromatic ring is increasing and the 450 $\mathrm{nm}$ band responsible for molecular stacking is decreasing (Figure 2a). FT-IR spectroscopy is an excellent technique to investigate the secondary structure and self-assembly pattern of the peptide. For peptide 1, the FT-IR band observed around $3332 \mathrm{~cm}^{-1}$ is responsible for hydrogen-bonded NH. However, the band at $3435 \mathrm{~cm}^{-1}$ indicates that all $\mathrm{NH}$ groups are not involved in intermolecular hydrogen bonding (Figure 2b). ${ }^{39}$ By POSS modification, the amide I band appeared at $1641 \mathrm{~cm}^{-1}$. For peptide 1 , there is an intense band around $1114 \mathrm{~cm}^{-1}$, characteristic of Si-O-Si linkage. ${ }^{40}$ The band at $1693 \mathrm{~cm}^{-1}$ confirms the antiparallel sheetlike structure (Figure $2 \mathrm{~b}$ inset). The powder X-ray diffraction of peptide 1 indicates a crystalline structure and shows multiple diffractions at $2 \theta=3.84,4.61$, $6.15,7.69,9.23,9.99,11.53,16.92,17.69,19.23$, and $20.76^{\circ}$ (Figure S2). The strongest scattering peak at $3.94^{\circ}(2 \theta)$ corresponds to a second-order diffraction and an antiparallel structure. $^{25}$ To investigate the role of different molecular functionalities in $\mathbf{1}$, we also studied the self-assembly of the building block 2 by different spectroscopic techniques (Figure S3). To investigate whether the hydrogen bonding is intramolecular or intermolecular, an NMR solvent titration experiment has been performed. To the solution of peptide $\mathbf{1}$ in
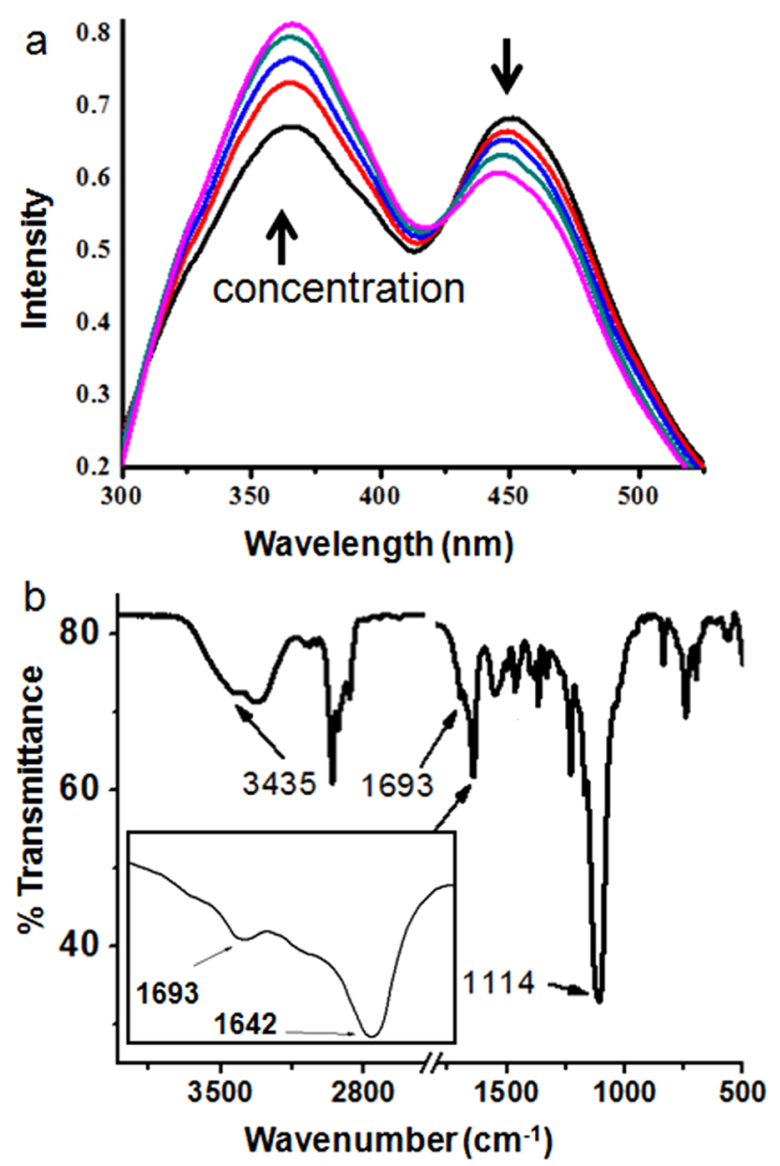

Figure 2. (a) Emission spectra of peptide 1 in DCM solution with increasing concentrations. (b) The solid-state FT-IR spectra of peptide 1 showing an antiparallel sheetlike structure.

$\mathrm{CDCl}_{3}, \mathrm{DMSO}-d_{6}$ was gradually added in $10 \mu \mathrm{L}$ amount at room temperature and NMR spectra were recorded. From Figure 3a, upon gradual addition of DMSO- $d_{6}$, a hydrogen bond-accepting solvent, to the $\mathrm{CDCl}_{3}$ solution of peptide 1 , the $\mathrm{NH}$ protons of peptide 1 get exposed to DMSO- $d_{6}$ and shift toward the downfield regions. For peptide 1, Boc NH and Phe (2) NH exhibit minimum chemical shifts $(\Delta \delta 0.40)$ even at higher percentages of $\left(\mathrm{CD}_{3}\right)_{2} \mathrm{SO}$. However, POSS $\mathrm{NH}$ shows the maximum chemical shift $(\Delta \delta 0.50)$. This result indicates that the peptide $\mathbf{1}$ forms an intermolecular hydrogen-bonded structure. $^{41,42}$ The aggregation propensities of the reported peptides were further studied by circular dichroism (CD) spectroscopy. The CD spectra of peptide 1 recorded from dilute methanol solution $\left(1 \times 10^{-6} \mathrm{M}\right)$ shows positive bands appearing at 202 and $209 \mathrm{~nm}$ and the negative cotton effect at 204 and $213 \mathrm{~nm}$ (Figure 3b). This indicates an antiparallel sheetlike structure for peptide 1 .

To investigate the effect of POSS on the morphology of the peptides, field emission scanning electron microscopic (FESEM) measurements were performed. The presence of POSS can dramatically affect the self-assembly and morphology due to their large volume and high steric hindrance. The DCM solution of the peptide was drop-casted on a clean glass slide and allowed to evaporate the solvent at room temperature for $12 \mathrm{~h}$ and dried under vacuum for 2 days. The FE-SEM images of peptide 1 show the formation of polydisperse microsphereslike morphology (Figure 4a,b). The average diameter of the microspheres is ca. $0.8 \mu \mathrm{m}$. The analysis of the FE-SEM images 

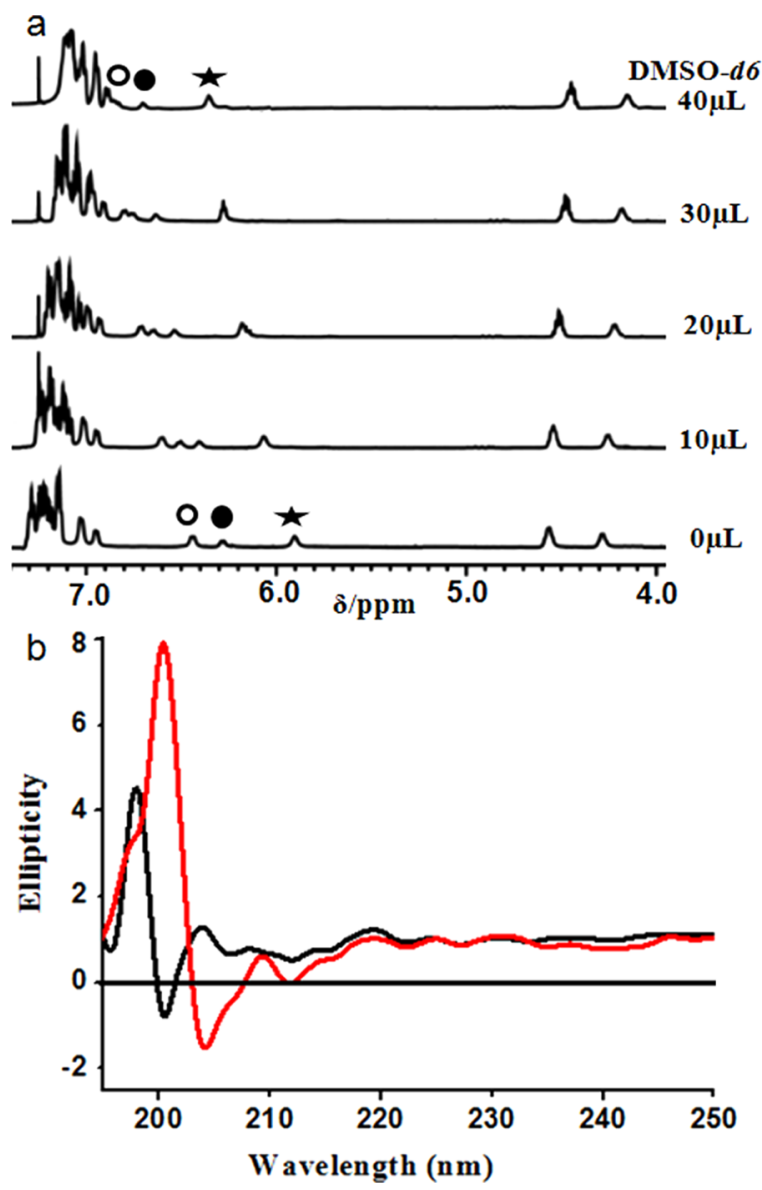

Figure 3. (a) Solvent dependence of the $\mathrm{NH}$ chemical shifts of peptide 1 at varying concentrations of $\left(\mathrm{CD}_{3}\right)_{2} \mathrm{SO}$ in $\mathrm{CDCl}_{3}$ solution. (b) $\mathrm{CD}$ spectra of peptide $\mathbf{1}$ (black) and peptide $\mathbf{2}$ (red) in methanol solution.

shows that the alignment and deposition of the microshperes cause enhancement of the surface roughness. Liu and coworkers have reported that the POSS self-assemble into a polydisperse layer structure by direct polymerization of multifunctional POSS-appended methylmethacrylate in the presence of benzoyl peroxide. ${ }^{43}$ To investigate the role of different molecular functionalities in $\mathbf{1}$ on morphologies, we also studied the self-assembly of the building blocks $\mathbf{2}$ and $\mathbf{3}$ (Figure $4 c, d$ ). tBoc-protected diphenylalanine 2 was moderately soluble in dichloromethane and the morphology appeared hexagonal nanotube in nature (Figure 4c). However, the dichloromethane solution of POSS 3 resulted in a nanocubelike structure (Figure 4d).

The enhanced surface roughness is a natural phenomenon used to control the water wettability of surfaces, such as lotus leaves. POSS is a well-defined cluster, with an inorganic core $\left(\mathrm{Si}_{8} \mathrm{O}_{12}\right)$, surrounded by eight organic groups and finds a widespread use in water-repellent coating. The diphenylalanine is also hydrophobic in nature. Overall, the hydrophobicity as well as the surface roughness (nanotexturation) of the selfassembled peptide 1 increases. So, the wettability of the peptide 1-coated surfaces should decrease. Indeed, the contact angle of a water droplet on the peptide 1-coated paper surface increases from $62^{\circ}$ (without coating) to $113^{\circ}$ (Figure S4). Thus, simply by coating with peptide 1 , the surface wettability of paper could be turned from hydrophilic to strongly hydrophobic. To illustrate the wettability decrease and shape retention, a folded paper without coating and a folded paper coated with peptide $\mathbf{1}$ were compared. ${ }^{44}$ The folded paper without coating could not unfold when it was folded and drenched with water (Figure 5a). However, under the same condition, the peptide 1-coated paper $(0.012 \mathrm{~mm})$ unfolds and recovers its original shape (Figure $5 b$ ). The morphology of the papers was studied by FESEM. As expected, the original paper exhibits a ribbonlike structure, in which individual fibers can be identified (Figure 5c). However, for peptide 1-coated paper, it is difficult to distinguish individual fibers and peptide 1 microspheres cover the paper surface with enhanced surface roughness (Figure $5 d$ ). Recently, Chung and co-workers have reported that POSS can be used to strengthen the mechanical properties of bioinspired adhesive. ${ }^{45}$ Figure $5 \mathrm{e}, \mathrm{f}$ shows the results of mechanical property experiments. The coating with peptide 1 increases the load
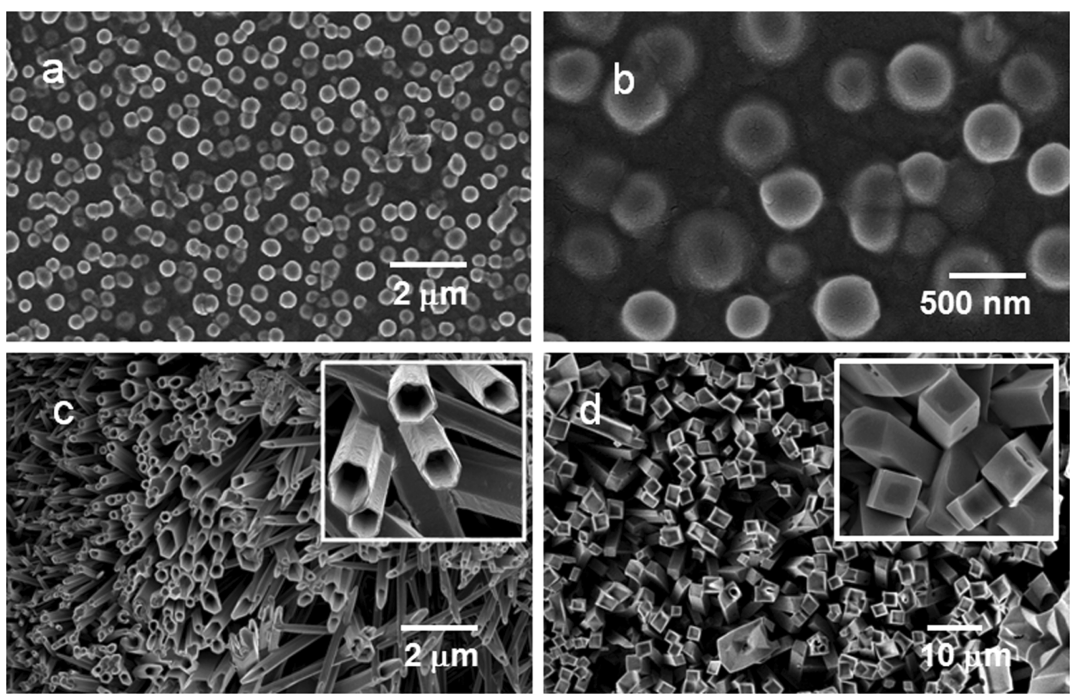

Figure 4. (a) FE-SEM image of peptide 1 showing polydisperse microspheres-like morphology with an enhanced surface. (b) The microspheres-like morphology of peptide $\mathbf{1}$ showing no pores in the microspheres. (c) FE-SEM images of peptide $\mathbf{2}$ showing nanotube-like structures. Inset shows the nanotubes as hexagonal in shape. (d) FE-SEM images of POSS 3 showing nanocube-like morphology. Inset shows that the nanocubes are hollow in nature. 

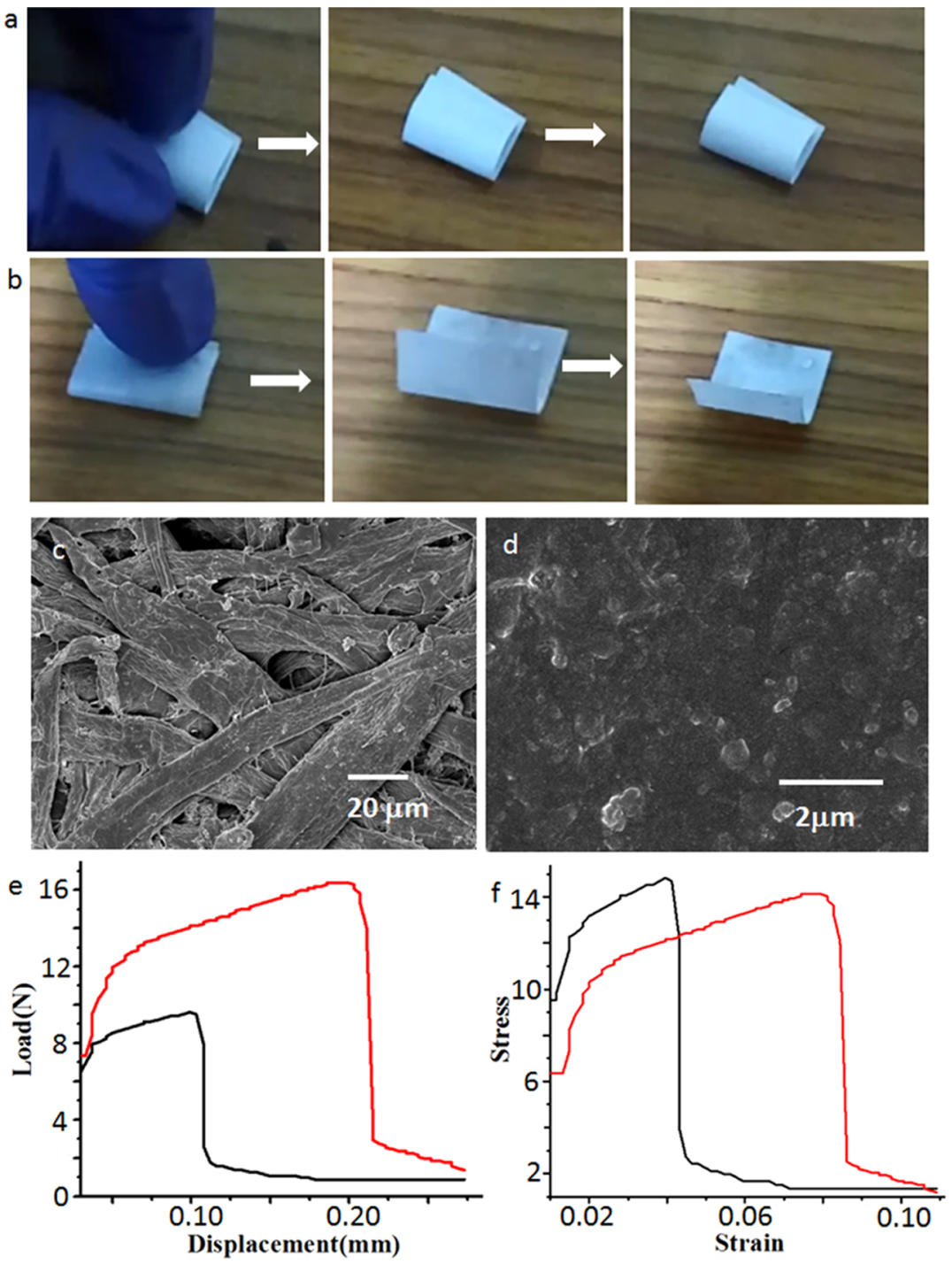

Figure 5. (a) A piece of paper after wetting and folding remains folded. (b) The piece of paper coated with compound 1, after wetting and folding. The paper unfolded once the pressure was taken off. (c) The FE-SEM image of the piece of paper showing fibrous morphology of cellulose. (d) The FE-SEM image of the piece of paper coated with compound 1 showing layers of microspheres above the cellulose fibers. (e) The load capacity curves of the normal paper (black) and peptide 1-coated paper (red). (f) The stress-strain curves of normal paper (black) and peptide 1-coated paper (red).

capacity of the paper 1.5 -fold (Figure 5e). Compared to that of the original uncoated paper, the elongation of the coated papers at the break increases 2-fold. The stress-strain curves of peptide 1-coated paper also show the decrease in the elastic modulus to 562 from $712 \mathrm{MPa}$ of the uncoated paper (Figure 5f). As a result, the peptide 1-coated paper not only increases the strength greatly but also the strain of the fibers, which improves the mechanical performance of the composites. The strength of a paper is due to the hydrogen-bonded network among overlapping cellulose fibers. When the paper has been coated with peptide 1 , the original hydrogen-bonded network of cellulose could be partially broken and replaced by the formation of new hydrogen bonds between peptide 1 and the hydroxyl groups of cellulose. Peptide $\mathbf{1}$ can also act as a binder among the cellulose fibers and significantly increase the strength and stability of paper. So, when the paper has been wetted with water, it shows excellent flexibility and shape retention.
To further investigate the topology of the hybrid material coating on paper, atomic force microscopic (AFM) studies were performed. The peptide solutions in dichloromethane (1 $\mathrm{mM}$ ) were dropcast on a paper, dried and investigated by AFM. The AFM image of the coated paper shows the formation of polydisperse microspheres morphology over the paper surface (Figure 6a). The three-dimensional (3D) image of coated paper surface indicates that the paper surface becomes very rough and the coating is very heterogeneous (Figure $6 \mathrm{~b}$ ). Figure $6 \mathrm{c}$ shows the surface of a noncoated paper.

Interestingly, the coated paper shows resistance toward bacterial growth. Figure 7a shows the growth of Escherichia coli on the paper surface under aqueous media. Under the same condition, the peptide 1-coated paper inhibits the growth of $E$. coli on the paper surface for up to 10 days (Figure $7 \mathrm{~b}$ ). Figure $S 15$ shows the growth of E. coli on the POSS 3-coated paper surface $(0.013 \mathrm{~mm})$ under aqueous media. This indicates that the peptide 1-coated paper is promising as an antibacterial water-resistant packing material. 

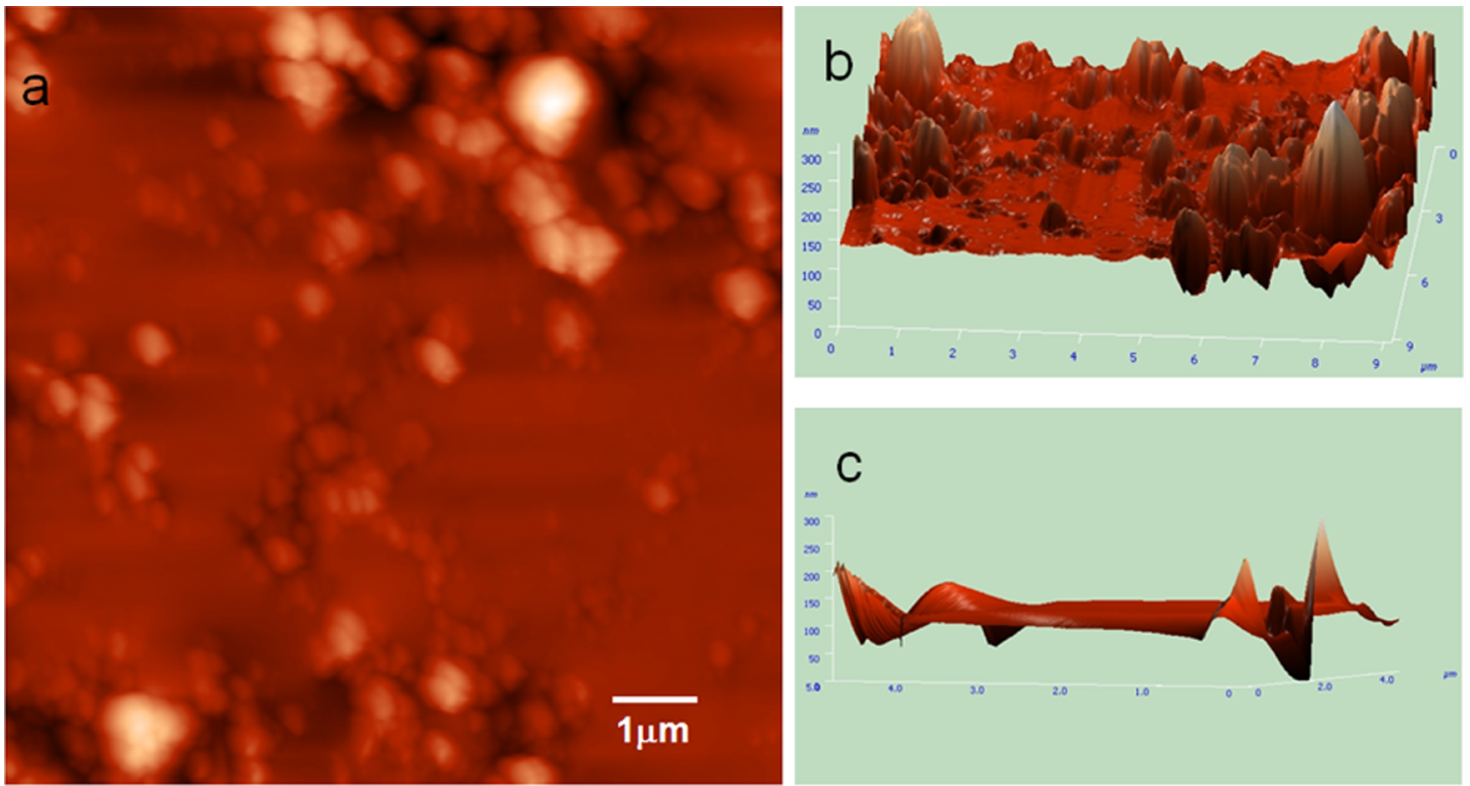

Figure 6. (a) AFM image of peptide 1-coated paper showing polydisperse microspheres-like morphology on the paper surface. (b) The 3D image shows that the surface of peptide 1-coated paper is very rough. (c) The 3D image of a paper surface without peptide 1 coating.
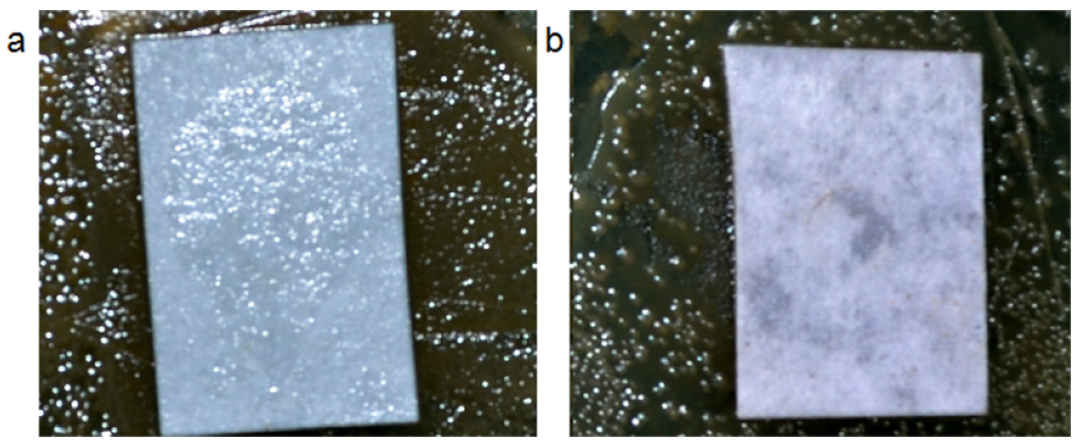

Figure 7. (a) Growth of the E. coli colony (the shiny white spots) on the paper surface. (b) Peptide 1-coated paper inhibits the growth of E. coli.

Furthermore, we have coated the iron surface with peptide $\mathbf{1}$. The same sample of noncoated iron nails got rusted by treatment with water under laboratory atmosphere. However, the iron nails coated with peptide $1(0.014 \mathrm{~mm})$ have no rust under the same condition. Then, we have coated half portion of an iron nail. The peptide $\mathbf{1}$ does not react with iron, and the coated part exhibits no color change (Figure $8 \mathrm{a}$ ). Figure $8 \mathrm{~b}$ shows the deposition of rust on the noncoated part of the iron nail due to treatment with water for $12 \mathrm{~h}$. Hence, peptide $\mathbf{1}$ acts as an antirusting and anticorrosion material. We have performed FE-SEM studies of the peptide 1-coated iron nail surface (Figure S5). We have also tested the antipollution properties of the peptide 1 coating. Environmental pollution is very harmful for artifacts. However, the protective coating that has color, acidity, basicity, or forms a thick layer can deform the artifact. So, an efficient, neutral, and thin layer of protective coating material is highly important for artifact preservation. We have coated half portion of a silver artifact by peptide $\mathbf{1}$. There is no color change or morphological change by coating with peptide 1 (Figure 8c). This indicates that silver does not react with peptide 1 . Figure $8 \mathrm{~d}$ shows the formation of black color silver sulfide on the noncoated part of the artifact surface after treatment with hydrogen sulfide for $1 \mathrm{~min}$.

We have also tested the resistance of the deposit to weathering. For that, we have coated a part of the iron nail
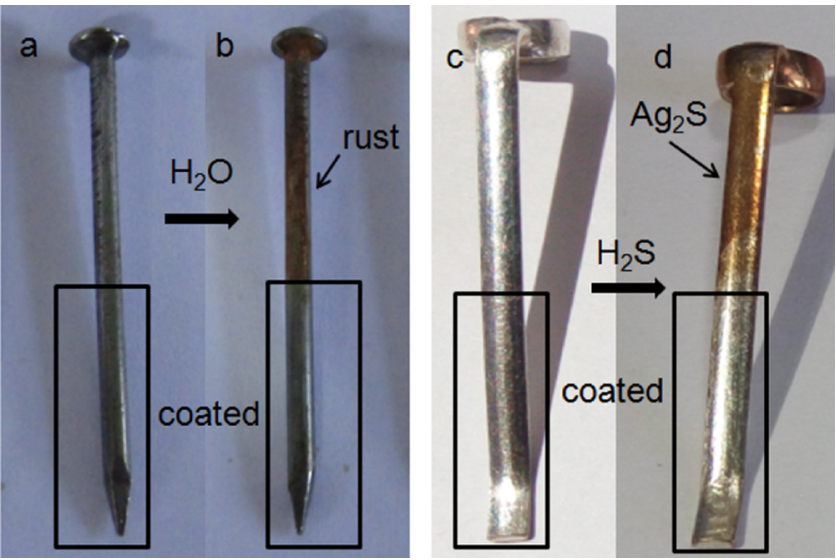

Figure 8. (a) Iron nail partially coated with peptide 1 . The coating is colorless and not visible with the naked eye. (b) The same iron nail after overnight treatment with water, showing rust on the noncoated portion. However, the coating with compound 1 prevents rust and corrosion. (c) A silver artifact partially coated with compound 1. (d) The silver artifact after contact with hydrogen sulfide. The compound 1-coated area is protected from hydrogen sulfide pollution.

surfaces by peptide 1 . Then, we have treated the iron nails with an aqueous solution of $\mathrm{NaCl}, \mathrm{KCl}, \mathrm{NaBr}, \mathrm{KBr}$, and $\mathrm{HCl}$. Figure 
9 shows the deposition of rust on the noncoated part of the iron nails. However, the parts of the iron nails coated with

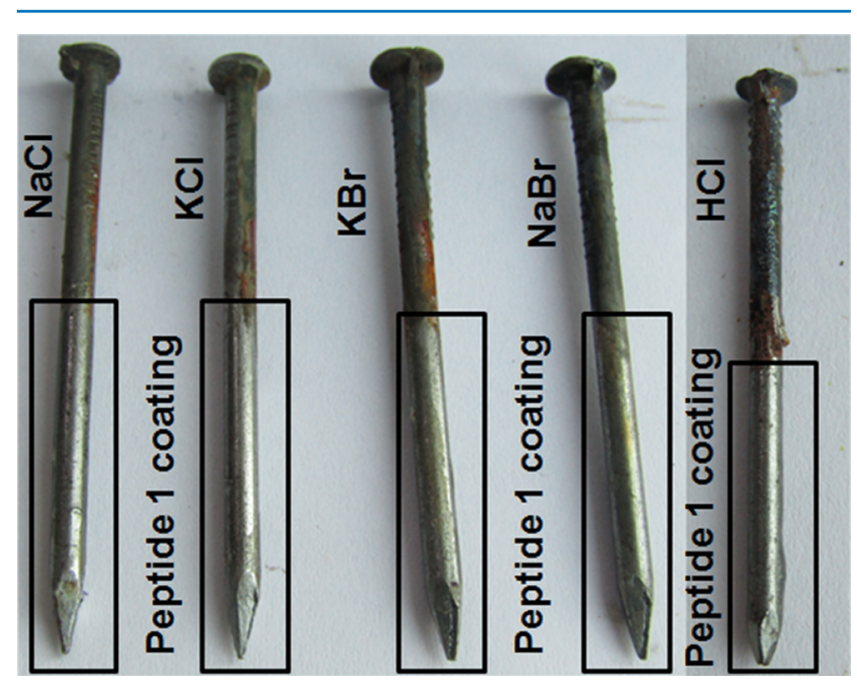

Figure 9. Iron nails partially coated with peptide 1 exhibit resistance to weathering from like $\mathrm{NaCl}, \mathrm{KCl}, \mathrm{KBr}, \mathrm{NaBr}$, and $\mathrm{HCl}$ at $\mathrm{pH} 2$.

peptide 1 have no change under weathering. Even at $\mathrm{pH} 2$, in $\mathrm{HCl}$ solution, the peptide 1-coated part exhibits no color change or corrosion.

The POSS molecule is known to have some fire-retardant property because during burning the $\mathrm{Si}-\mathrm{C}$ bonds get cleaved and form stable silicon-oxycarbide black glass surface on the materials. ${ }^{46}$ The thermogravimetric analysis plots show that the thermal stabilization of peptide $\mathbf{1}$ is higher than that of peptide 2 and POSS 3 (Figure S21). The POSS moiety has a significantly low melting point and it melts at near to $56{ }^{\circ} \mathrm{C}$ (Figure 10a) and comes out from the surface of the materials and thus the fire retardancy effectively decreases. However, the differential scanning calorimetry (DSC) experiments show that the POSS-appended peptide $\mathbf{1}$ has significant thermal stability. Peptide 1 exhibits no decomposition, phase transition, or mass loss for up to $130{ }^{\circ} \mathrm{C}$ (Figure 10a). Fire-resistant coating has been extensively studied for fire-retardant applications at high temperatures and extended times. The coating should have relatively good thermal stability as well as processibility and be a true fire barrier for a wide variety of materials, including wood. We have performed the fire retardation experiments with highly flammable match sticks. The experimental strategy was to test whether the POSS-appended peptide 1 can stop the spreading fire. So, we have coated the tail of the match stick with peptide 1 (Figure 10b). Similarly, the other sets of match sticks were coated with only POSS 3 and peptide 2 in the DCM solution. The match stick without coating burnt completely (Figure 10c). For peptide 1, during the experiments we have seen that in the beginning fire catches the head of the sticks and it spreads to the tail of the sticks (Figure 10c). Initially, the flame smoothly covers the uncoated portion of the stick and as soon as the flame reaches the coated portion it gets retarded instantly, and after a few seconds the flames extinguis suddenly, leaving the peptide 1 -coated portion $(0.030 \mathrm{~mm})$ of the stick unburned (Figure 10c). There is no additional smoke or bad smell. But for the POSS 3-coated stick $(0.031 \mathrm{~mm})$ in an identical condition, the flame takes significantly more time to reach the tail of the stick; the fire does not get extinguished (Figure 10c). However, for the sticks coated with peptide 2

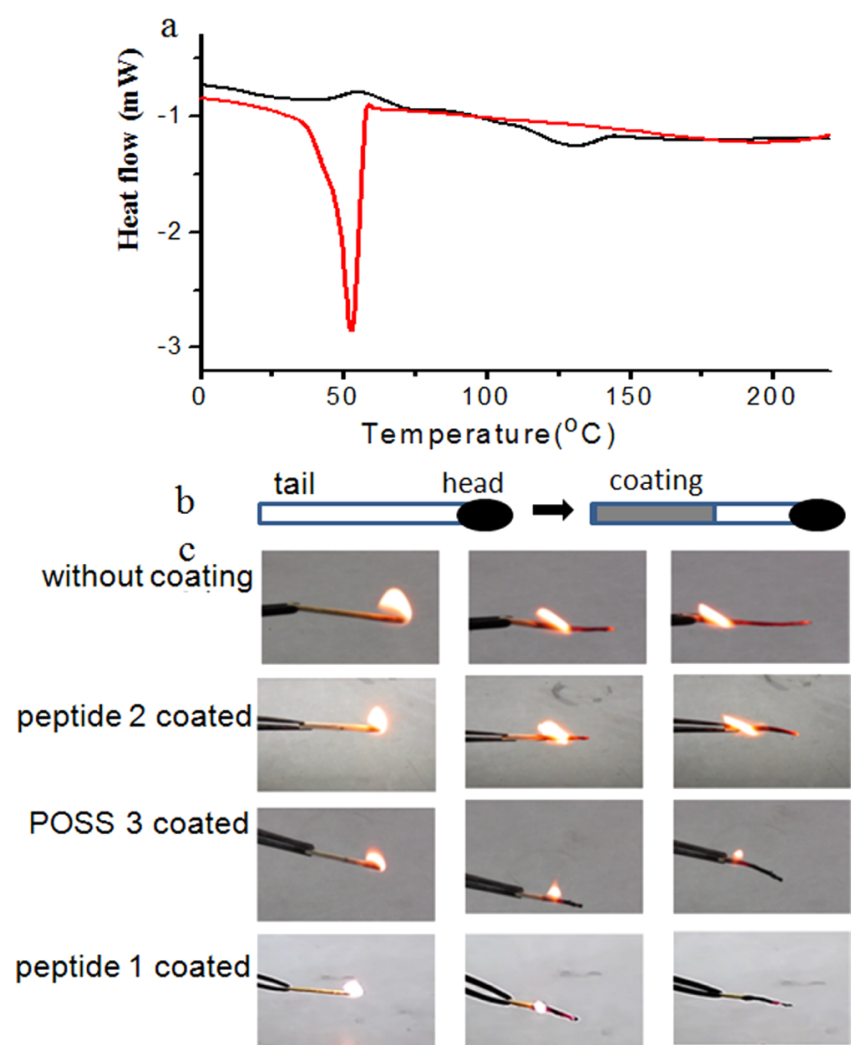

Figure 10. (a) DSC plot of only POSS (red) and peptide 1 (black). (b) The schematic of the match stick coating with peptide. (c) Fireretardant experiment of match sticks with or without coating, coated with peptide 2 , POSS 3 , and peptide $\mathbf{1}$, at different time intervals.

$(0.031 \mathrm{~mm})$, the whole stick burnt quickly (Figure 10c). So, the coating of only POSS 3 retards the flame whereas POSSappended peptide 1 not only retards the flame but also extinguishes the fire.

\section{CONCLUSIONS}

In conclusion, we report a novel multifunctional self-cleaning organic-inorganic hybrid material from diphenylalanine and POSS. The incorporation of POSS increases hardness, stability, and thermo compatibility of the hybrid material and the diphenylalanine-directed aggregation propensities. Peptide 1 forms an antiparallel structure and exhibits polydisperse microspheres morphology. The deposition of the microspheres on any surface enhances its roughness and hydrophobicity. The POSS-appended peptide-coated paper exhibits unique water resistance property and elasticity and enhances mechanical strength and inhibits bacterial colony growth. Moreover, the colorless hydrophobic coating of the hybrid material prevents rusting of iron and decreases corrosion. The coated match stick experiments have shown that POSS-appended diphenylalanine not only retards the flame but also extinguishes the fire. These findings show that the self-cleaning hybrid materials, with their novel properties, are promising for the packaging industry and metal industry and protect artifacts from corrosion and environmental pollution.

\section{EXPERIMENTAL SECTION}

General. All chemicals were purchased from Sigma Chemicals. 
Synthesis. The reported peptide was synthesized by the conventional solution-phase methodology using racemizationfree fragment condensation strategy. The tertiary butoxycarbonyl group was used for $\mathrm{N}$-terminal protection, and the $\mathrm{C}$ terminus was protected as a methyl ester. Couplings were mediated by DCC/1-hydroxybenzotriazole ( $\mathrm{HOBt})$. The products were purified by column chromatography using silica (100-200-mesh size) gel as the stationary phase and $n$ hexane-ethyl acetate mixture as the eluent. The final compound was fully characterized by $500 \mathrm{MHz}{ }^{1} \mathrm{H}$ NMR spectroscopy, ${ }^{13} \mathrm{C}$ NMR spectroscopy, MS, and IR spectroscopy.

Synthesis of Boc-Phe(1)-Phe(2)-OMe 4. Boc-Phe-OH (1.85 $\mathrm{g}, 7 \mathrm{mmol}$ ) was dissolved in $20 \mathrm{~mL}$ of dry DCM in an icewater bath. H-Phe-OMe was isolated from $3.09 \mathrm{~g}(14 \mathrm{mmol})$ of the corresponding methyl ester hydrochloride by neutralization and subsequent extraction with ethyl acetate and the ethyl acetate extract was concentrated to $10 \mathrm{~mL}$. It was then added to the reaction mixture, followed by immediate addition of $1.44 \mathrm{~g}$ (7 mmol) of DCC and $0.95 \mathrm{~g}(7 \mathrm{mmol})$ of HOBt. The reaction mixture was allowed to reach the room temperature and stirred for $48 \mathrm{~h}$. After that, DCM was evaporated and the residue was dissolved in ethyl acetate $(60 \mathrm{~mL})$, and dicyclohexyl urea (DCU) was filtered off. The organic layer was washed with $2 \mathrm{M}$ $\mathrm{HCl}(3 \times 50 \mathrm{~mL})$, brine $(2 \times 50 \mathrm{~mL}), 1 \mathrm{M}$ sodium carbonate $(3 \times 50 \mathrm{~mL})$, and brine $(2 \times 50 \mathrm{~mL})$ and dried over anhydrous sodium sulfate. The solution was evaporated under vacuum to obtain dipeptide (1) as a white solid. The product was purified by silica gel (100-200 mesh) using $n$-hexane-ethyl acetate $(3: 1)$ as the eluent.

Yield: $2.34 \mathrm{~g}$ (5.50 mmol 78.6\%).

${ }^{1} \mathrm{H}$ NMR (500 MHz, $\mathrm{CDCl}_{3}, \delta$ in ppm): $7.22-7.13(\mathrm{~m}, 8 \mathrm{H}$, aromatic protons); 6.94-6.92 (m, $2 \mathrm{H}$, aromatic protons); 6.93 (b, 1H, NH); 5.0 (b, 1H, Boc NH); $4.72\left(\mathrm{~s}, 1 \mathrm{H}, \mathrm{C}^{\alpha} \mathrm{H} \mathrm{Phe}^{1}\right)$; 4.30 (s, 1H, $\mathrm{C}^{\beta} \mathrm{H} \mathrm{Phe}^{2}$ ); 3.6 (s, 3H, OMe); 2.99-2.96 (m, 4H, $\mathrm{C}^{\beta} \mathrm{H} \mathrm{Phe}^{1}, \mathrm{C}^{\beta} \mathrm{H} \mathrm{Phe}^{2}$ ); 1.34 (s, 9H, Boc). ${ }^{13} \mathrm{C}$ NMR (125 MHz, $\mathrm{CDCl}_{3}, \delta$ in ppm): 171.48, 170.99, 155.39, 136.62, 135.75, $129.62,129.45,128.71,128.62,127.18,127.02,80.24,55.74$, 53.38, 52.35, 28.33. IR (KBr): $\nu=3332 \mathrm{~cm}^{-1}(\mathrm{w}), 1736 \mathrm{~cm}^{-1}$ (w); UV-vis (DCM): $\lambda_{\max }(\varepsilon)=256 \mathrm{~nm}\left(605 \mathrm{M}^{-1} \mathrm{~cm}^{-1}\right), 226$ $\mathrm{nm}\left(2133 \mathrm{M}^{-1} \mathrm{~cm}^{-1}\right)$.

Synthesis of Boc-Phe(1)-Phe-(2)-OH 2. To $1.27 \mathrm{~g} \mathrm{(3} \mathrm{mmol)}$ of Boc-Phe-Phe-OMe, $15 \mathrm{~mL}$ of $\mathrm{MeOH}$ and $4.5 \mathrm{~mL}(2 \mathrm{M})$ of $\mathrm{NaOH}$ were added, and the progress of saponification was monitored by thin layer chromatography. The reaction mixture was stirred. After $10 \mathrm{~h}$, methanol was removed under vacuum; the residue was dissolved in $50 \mathrm{~mL}$ of water and washed with diethyl ether $(2 \times 50 \mathrm{~mL})$. Then, the $\mathrm{pH}$ of the aqueous layer was adjusted to 2 using $1 \mathrm{M} \mathrm{HCl}$, and it was extracted with ethyl acetate $(3 \times 50 \mathrm{~mL})$. The extracts were pooled, dried over anhydrous sodium sulfate, and evaporated under vacuum to obtain the compound as a waxy solid.

Yield: $1.18 \mathrm{~g}$ (2.88 mmol, 96\%).

${ }^{1} \mathrm{H}$ NMR (500 MHz, DMSO- $d_{6}, \delta$ in ppm): 7.5-7.12 (m, $10 \mathrm{H}$, aromatic protons; $2 \mathrm{H}, \mathrm{NH}$ protons $) ; 4.07-4.02(\mathrm{~m}, 2 \mathrm{H}$, $\mathrm{C}^{\alpha} \mathrm{H}$ protons, Phe $(1)$ and Phe $(2) ; 3.12-3.08(\mathrm{~m}, 1 \mathrm{H}) ; 3.0-$ $2.90(\mathrm{~m}, 2 \mathrm{H}) ; 2.7-2.6\left(\mathrm{~m}, 1 \mathrm{H}, \mathrm{C}^{\beta} \mathrm{H} \mathrm{Phe}^{2}\right) ; 1.33-1.22(\mathrm{~s}, 9 \mathrm{H}$, Boc). ${ }^{13} \mathrm{C}$ NMR $\left(125 \mathrm{MHz}, \mathrm{DMSO}-d_{6}, \delta\right.$ in ppm): 173.08, $170.34,155.19,139.16,138.68,129.77,129.10,127.97,127.53$, 125.49, 78.01, 56.49, 55.34, 28.14. IR (KBr): $\nu=3432 \mathrm{~cm}^{-1}$ (w), $1641 \mathrm{~cm}^{-1}(\mathrm{w}) ; \mathrm{UV}-$ vis (DCM): $\lambda_{\max }(\varepsilon)=259 \mathrm{~nm}$ $\left(1150 \mathrm{M}^{-1} \mathrm{~cm}^{-1}\right), 229 \mathrm{~nm}\left(2571 \mathrm{M}^{-1} \mathrm{~cm}^{-1}\right)$.
Synthesis of Boc-Phe(1)-Phe(2)-POSS 1. Boc-Phe-Phe-OH $(0.61 \mathrm{~g}, 1.5 \mathrm{mmol})$ was dissolved in $20 \mathrm{~mL}$ of dry DCM in an ice-water bath. $\mathrm{H}$ - $\left(\mathrm{CH}_{2}\right)_{4}$-POSS $(1.3 \mathrm{~g}, 1.5 \mathrm{mmol})$ was added to the reaction mixture, followed by the immediate addition of $0.30 \mathrm{~g}(1.5 \mathrm{mmol})$ of DCC and $0.20 \mathrm{~g}(1.5 \mathrm{mmol})$ of HOBt. The reaction mixture was allowed to reach the room temperature and stirred for $48 \mathrm{~h}$. After that, DCM was evaporated and the residue was dissolved in ethyl acetate (60 $\mathrm{mL})$, and DCU was filtered off. The organic layer was washed with $2 \mathrm{M} \mathrm{HCl}(3 \times 50 \mathrm{~mL})$, brine $(2 \times 50 \mathrm{~mL}), 1 \mathrm{M}$ sodium carbonate $(3 \times 50 \mathrm{~mL})$, and brine $(2 \times 50 \mathrm{~mL})$ and dried over anhydrous sodium sulfate. The solution was evaporated under vacuum to obtain POSS-based peptide (3) as a white solid. The product was purified by silica gel (100-200 mesh), using $n$ hexane-ethyl acetate $(9: 1)$ as the eluent.

Yield: $1.39 \mathrm{~g}(1.1 \mathrm{mmol}, 73.3 \%)$.

${ }^{1} \mathrm{H}$ NMR (500 MHz, $\mathrm{CDCl}_{3}, \delta$ in ppm): $7.28-7.15(\mathrm{~m}, 8 \mathrm{H}$, aromatic protons); $7.05-6.95$ (m, $2 \mathrm{H}$, aromatic protons); 6.45 (b, 1H, NH); 6.25 (b, 1H, NH); 5.90 (b, 1H, Boc NH); 4.56 (m, 1H, C $\left.{ }^{\alpha} \mathrm{H}^{\mathrm{Phe}}{ }^{1}\right) ; 4.28\left(\mathrm{~m}, 1 \mathrm{H}, \mathrm{C}^{\alpha} \mathrm{H} \mathrm{Phe}^{2}\right) ; 3.22-3.06(\mathrm{~m}$, $\left.4 \mathrm{H}, \mathrm{C}^{\beta} \mathrm{H} \mathrm{Phe}^{1}, \mathrm{C}^{\beta} \mathrm{H} \mathrm{Phe}^{2}\right)$; 3.05-2.80 (m, 2H, $\mathrm{C}^{\gamma} \mathrm{H}$ of $\mathrm{Si}$ ); $1.85-1.81\left(\mathrm{~m}, 9 \mathrm{H}, \mathrm{C}^{\beta} \mathrm{H} \mathrm{Si}\right.$ ); $1.32-1.30$ (s, 9H, Boc); 0.960.92 (d, 42H); $0.61-0.58$ (d, $16 \mathrm{H}) .{ }^{13} \mathrm{C}$ NMR $(125 \mathrm{MHz}$ $\mathrm{CDCl}_{3}, \delta$ in ppm): $171.45,171.25,170.40,136.88,136.63$, $129.85,129.70,129.24,129.11,127.64,127.46,85.58,57.26$, $56.44,54.43,42.42,38.5,28.62,26.14,24.32,23.04,9.91 .{ }^{29} \mathrm{Si}$ NMR (125 MHz, $\mathrm{CDCl}_{3}, \delta$ in ppm): $-68.52,-68.74$. IR $(\mathrm{KBr}): \nu=3435 \mathrm{~cm}^{-1}(\mathrm{w}), 1641 \mathrm{~cm}^{-1}(\mathrm{w}), 1114 \mathrm{~cm}^{-1}$ (SiOSi); UV-vis $(\mathrm{DCM}): \lambda_{\max }(\varepsilon)=259 \mathrm{~nm}\left(2343 \mathrm{M}^{-1} \mathrm{~cm}^{-1}\right), 229 \mathrm{~nm}$ $\left(3462 \mathrm{M}^{-1} \mathrm{~cm}^{-1}\right)$; mass spectra: $m / z$ 1291.51; $[\mathrm{M}+\mathrm{Na}]^{+}$; $M_{\text {Calculated }} 1268.77$.

NMR Experiments. All NMR studies were carried out on a Brüker AVANCE $500 \mathrm{MHz}$ spectrometer. Compound concentrations were in the range $1-10 \mathrm{~mm}$ in DMSO-d6, $\mathrm{CDCl}_{3}$.

FT-IR Spectroscopy. All reported solid-state FT-IR spectra were obtained with a Perkin Elmer Spectrum RX1 spectrophotometer, with the $\mathrm{KBr}$ disk technique and in $\mathrm{MeOH}$ solution.

MS. Mass spectra were recorded on a Q-Tof Micro YA263 high-resolution (Waters Corporation) mass spectrometer by positive-mode electrospray ionization.

FE-SEM. Morphologies of the reported compounds were investigated using FE-SEM. A small amount of each sample solution was placed on a clean glass slide and then dried by slow evaporation. The material was then allowed to dry under vacuum at $30{ }^{\circ} \mathrm{C}$ for 2 days. The materials were gold-coated, and the micrographs were taken in an FE-SEM apparatus (Jeol Scanning Microscope-JSM-6700F).

AFM. The morphology of the reported compound was investigated by AFM. A small amount of the dichloromethane solution of peptide 1 was placed on a paper and then dried by slow evaporation. The material was then allowed to dry under vacuum at $30{ }^{\circ} \mathrm{C}$ for 2 days. Images were taken with an NTMDT instrument, model no. AP-0100 in the semicontact mode.

Wide-Angle X-ray Diffraction Study. The wide-angle Xray scattering pattern was made on the solid of peptide 1 . The experiment was carried out in a Rigaku X-ray diffractometer (C $3000)$ with a parallel beam optics attachment. The instrument was operated at $45 \mathrm{kV}$ voltage and $200 \mathrm{~mA}$ current and was calibrated with a standard silicon sample. The sample was scanned from 5 to $60^{\circ}(2 \theta)$ in the step scan mode (step size $0.02^{\circ}$, preset time $2 \mathrm{~s}$ ), and the diffraction pattern was recorded 
using a scintillation scan detector. The wavelength of the X-ray source is $1.5418 \AA$ ( $\mathrm{K} \alpha$ value of $\mathrm{Cu})$.

CD Spectroscopy. CD study of the reported peptides in methanol has been carried out on a JASCO J-815-150S instrument at a temperature of $25{ }^{\circ} \mathrm{C}$.

DSC. To investigate the change of the thermal behavior, DSC experiments were performed. The DSC experiments were done in a METTLER DSC instrument under a $\mathrm{N}_{2}$ atmosphere. As-synthesized materials and xerogels were taken in aluminum standard $40 \mathrm{~mL}$ vessels with a pin, tightened with an O-ring. These samples were then heated from -30 to $250{ }^{\circ} \mathrm{C}$ at a heating rate of $10^{\circ} \mathrm{C} / \mathrm{min}$. The instrument was calibrated with indium and cyclohexane.

Bacteriological Study. The growth of E. coli on the paper surface under aqueous media has been monitored. Under same condition, the peptide 1-coated paper inhibits the growth of $E$. coli on the paper surface, for up to 10 days.

Rusting Study. One iron nail was dipped in dichloromethane solution of peptide 1 and dried. Then, we coated half a portion of another iron nail with dichloromethane solution of peptide 1 and dried. The peptide 1 does not react with iron and the coated part exhibits no color change. The third nail was without any coating and used as control. All three nails were treated with water for $12 \mathrm{~h}$.

$\mathrm{H}_{2} \mathrm{~S}$ Pollution Study. Half a portion of a silver artifact was coated by peptide $\mathbf{1}$ solution in dichloromethane. There is no color change or morphological change by coating with peptide 1. Then, the artifact was treated with hydrogen sulfide gas for $\mathbf{1}$ $\min$.

\section{ASSOCIATED CONTENT}

\section{S Supporting Information}

The Supporting Information is available free of charge on the ACS Publications website at DOI: 10.1021/acsomega.7b00234.

Synthesis and characterization of the compounds, ${ }^{1} \mathrm{H}$ NMR, ${ }^{13} \mathrm{C}$ NMR, and ${ }^{29} \mathrm{Si}$ NMR and Figures $\mathrm{S} 1-\mathrm{S} 22$ (PDF)

\section{AUTHOR INFORMATION}

\section{Corresponding Author}

*E-mail: deba_h76@yahoo.com, deba_h76@iiserkol.ac.in.

\section{ORCID}

Debasish Haldar: 0000-0002-7983-4272

\section{Author Contributions}

K.M. has synthesized the compound and done the experiments. D.H. has done the analysis and written the manuscript.

\section{Notes}

The authors declare no competing financial interest.

\section{ACKNOWLEDGMENTS}

We acknowledge the CSIR, India, for financial assistance (Project No. 02(0206)/14/EMR-II). This work is also supported by IISER Kolkata, India (fellowship to K.M.). We are thankful to Dr. P. De, IISER Kolkata, for the supply of POSS 3.

\section{REFERENCES}

(1) Romero, P. G.; Sanchez, C. Functional Hybrid Materials; WileyVCH: Wienheim, 2004; pp 1-434.

(2) Lee, C. F.; Leigh, D. A.; Pritchard, R. G.; Schultz, D.; Teat, S. J.; Timco, G. A.; Winpenny, R. E. P. Hybrid organic-inorganic rotaxanes and molecular shuttles. Nature 2009, 458, 314-318.
(3) Coe, S.; Woo, W. K.; Bawendi, M.; Bulović, V. Electroluminescence from single monolayers of nanocrystals in molecular organic devices. Nature 2002, 420, 800-803.

(4) Saparov, B.; Mitzi, D. B. Organic-inorganic perovskites: structural versatility for functional materials design. Chem. Rev. 2016, $116,4558-4596$.

(5) Bera, S.; Haldar, D. A rechargeable self-healing safety fuel gel. J. Mater. Chem. A 2016, 4, 6933-6939.

(6) Loy, D. A.; Shea, K. J. Bridged polysilsesquioxanes. Highly porous hybrid organic-inorganic materials. Chem. Rev. 1995, 95, 1431-1442.

(7) Tanaka, K.; Chujo, Y. Advanced functional materials based on polyhedral oligomeric silsesquioxane (POSS). J. Mater. Chem. 2012, $22,1733-1746$.

(8) Laine, R. M. Nanobuilding blocks based on the $\left[\mathrm{OSiO}_{1.5}\right]_{x}(x=6$, 8, 10) octasilsesquioxanes. J. Mater. Chem. 2005, 15, 3725-3744.

(9) Feher, F. J.; Newman, D. A.; Walzer, J. F. Silsesquioxanes as models for silica surfaces. J. Am. Chem. Soc. 1989, 111, 1741-1748.

(10) Miyazato, A.; Pakjamsai, C.; Kawakami, Y. Octa, deca, and dodeca (4-nitrophenyl) cage silsesquioxanes via 4-trimethylsilylphenylderivatives. Dalton Trans. 2010, 39, 3239-3244.

(11) Cordes, D. B.; Lickiss, P. D.; Rataboul, F. Recent developments in the chemistry of cubic polyhedral oligosilsesquioxanes. Chem. Rev. 2010, 110, 2081-2173.

(12) Zhang, W. A.; Fang, B.; Walther, A.; Muller, A. H. E. Synthesis via RAFT polymerization of tadpole-shaped organic/inorganic hybrid poly(acrylic acid) containing polyhedral oligomeric silsesquioxane (POSS) and their self-assembly in water. Macromolecules 2009, 42, 2563-2569.

(13) Ye, Q.; Zhou, H.; Xu, J. Cubic polyhedral oligomeric silsesquioxane based functional materials: synthesis, assembly, and applications. Chem. Asian J. 2016, 11, 1322-1337.

(14) Aziz, Y. E.; Bassindale, A. R.; Taylor, P. G.; Stephenson, R. A.; Hursthouse, M. B.; Harrington, R. W.; Clegg, W. X-ray Crystal Structures, Packing Behavior, and Thermal Stability Studies of a Homologous Series of n-Alkyl-Substituted Polyhedral Oligomeric Silsesquioxanes. Macromolecules 2013, 46, 988-1001.

(15) Ervithayasuporn, V.; Abe, J.; Wang, X.; Matsushima, T.; Murata, H.; Kawakami, Y. Synthesis, characterization, and OLED application of oligo(p-phenylene ethynylene)s with polyhedral oligomeric silsesquioxanes (POSS) as pendant groups. Tetrahedron 2010, 66, 93489355.

(16) Nguyen, T. P.; Lee, C. W.; Hassen, S.; Le, H. C. Hybrid nanocomposites for optical applications. Solid State Sci. 2009, 11, $1810-1814$.

(17) Majumdar, P.; Lee, E.; Gubbins, N.; Stafslien, S. J.; Daniels, J.; Thorson, C. J.; Chisholm, B. J. Synthesis and antimicrobial activity of quaternary ammonium-functionalized POSS (Q-POSS) and polysiloxane coatings containing Q-POSS. Polymer 2009, 50, 1124-1133.

(18) Feher, F. J.; Tajima, T. L. Synthesis of a molybdenumcontaining silsesquioxane which rapidly catalyzes the metathesis of olefins. J. Am. Chem. Soc. 1994, 116, 2145-2146.

(19) Wang, F.; Lub, X.; He, C. Some recent developments of polyhedral oligomeric silsesquioxane (POSS)-based polymeric materials. J. Mater. Chem. 2011, 21, 2775-2782.

(20) Tanaka, K.; Chujo, Y. Advanced functional materials based on polyhedral oligomeric silsesquioxane (POSS). J. Mater. Chem. 2012, 22, 1733-1746.

(21) Dule, M.; Biswas, M.; Paira, T. K.; Mandal, T. K. Hierarchical nanostructures of tunable shapes through self-aggregation of POSS end-functional polymer and poly(ionic liquid) hybrids. Polymer 2015, $77,32-41$.

(22) Zhang, L.; Abbenhuis, H. C. L.; Yang, Q.; Wang, Y. M.; Magusin, P. C. M.; Mezari, M. B.; van Santen, R. A.; Li, C. Mesoporous organic-inorganic hybrid materials built using polyhedral oligomeric silsesquioxane blocks. Angew. Chem., Int. Ed. 2007, 46, $5003-5006$

(23) Waddon, A. J.; Coughlin, E. B. Crystal structure of polyhedral oligomeric silsequioxane (POSS) nano-materials: A study by X-ray 
diffraction and electron microscopy. Chem. Mater. 2003, 15, 45554561.

(24) Haldar, U.; Pan, A.; Mukherjee, I.; De, P. POSS semitelechelic $\mathrm{A} \beta_{17-19}$ peptide initiated helical polypeptides and their structural diversity in aqueous medium. Polym. Chem. 2016, 7, 6231-6240.

(25) Zhou, H.; Li, J.; Chua, M. H.; Yan, H.; Ye, Q.; Song, J.; Lin, T. T.; Tang, B. Z.; Xu, J. Tetraphenylethene (TPE) modified polyhedral oligomeric silsesquioxanes (POSS): unadulterated monomer emission, aggregation-induced emission and nanostructural self-assembly modulated by the flexible spacer between POSS and TPE. Chem. Commun. 2016, 52, 12478-12481.

(26) Pu, Y. J.; Yang, H.; Yang, M.; He, B.; Gu, Z. W. Synthesis of peptide dendrimers with polyhedral oligomeric silsesquioxane cores via click chemistry. Chin. Chem. Lett. 2013, 24, 917-920.

(27) Mannige, R. V.; Haxton, T. K.; Proulx, C.; Robertson, E. J.; Battigelli, A.; Butterfoss, G. L.; Zuckermann, R. N.; Whitelam, S. Peptoid nanosheets exhibit a new secondary-structure motif. Nature 2015, 526, 415-420.

(28) Pham, J. D.; Spencer, R. K.; Chen, K. H.; Nowick, J. S. Polymorphism of oligomers of a peptide from $\beta$-amyloid. J. Am. Chem. Soc. 2014, 136, 12682-12690.

(29) Ghadiri, M. R.; Granja, J. R.; Buehler, L. K. Artificial transmembrane ion channels from self-assembling peptide nanotubes. Nature 1994, 369, 301-304.

(30) Hourani, R.; Zhang, C.; Weegen, R.; Ruiz, L.; Li, C.; Keten, S.; Helms, B. A.; Xu, T. Processable cyclic peptide nanotubes with tunable interiors. J. Am. Chem. Soc. 2011, 133, 15296-15299.

(31) Yan, X.; Zhu, P.; Li, J. Self-assembly and application of diphenylalanine-based nanostructures. Chem. Soc. Rev. 2010, 39, $1877-1890$.

(32) Amdursky, N.; Molotskii, M.; Gazit, E.; Rosenman, G. Elementary Building Blocks of Self-assembled peptide nanotubes. J. Am. Chem. Soc. 2010, 132, 15632-15636.

(33) Hauser, C. A. E.; Zhang, S. Nanotechnology: Peptides as biological semiconductors. Nature 2010, 468, 516-517.

(34) Kholkin, A.; Amdursky, N.; Bdikin, I.; Gazit, E.; Rosenman, G. Strong piezoelectricity in bioinspired peptide nanotubes. ACS Nano 2010, 4, 610-614.

(35) Kol, N.; Abramovich, L. A.; Barlam, D.; Shneck, R. Z.; Gazit, E.; Rousso, I. Self-assembled peptide nanotubes are uniquely rigid bioinspired supramolecular structures. Nano Lett. 2005, 5, 1343-1346.

(36) Abramovich, L. A.; Recahes, M.; Sedman, V.; Allen, L. S.; Tendler, S. J. B.; Gazit, E. Thermal and chemical stability of diphenylalanine peptide nanotubes: implications for nanotechnological applications. Langmuir 2006, 22, 1313-1320.

(37) Niu, L.; Chen, X.; Allen, S.; Tendler, S. J. B. Using the bending beam model to estimate the elasticity of diphenylalanine nanotubes. Langmuir 2007, 23, 7443-7446.

(38) Reches, M.; Gazit, E. Casting metal nanowires within discrete self-assembled peptide nanotubes. Science 2003, 300, 625-627.

(39) Moretto, V.; Crisma, M.; Bonora, G. M.; Toniolo, C.; et al. Comparison of the effect of five guest residues on the beta sheet conformation of host (L-Val)n oligopeptides. Macromolecules 1989, 22, 2939-2944.

(40) Wang, F.; Luand, X.; He, C. Some recent developments of polyhedral oligomeric silsesquioxane(POSS)-based polymeric materials. J. Mater. Chem. 2011, 21, 2775-2782.

(41) Maji, K.; Sarkar, R.; Bera, S.; Haldar, D. A small molecule peptidomimetic of spider silk and webs. Chem. Commun. 2014, 50, 12749-12752.

(42) Maity, S. K.; Maity, S.; Jana, P.; Haldar, D. Supramolecular double helix from capped $\gamma$-peptide. Chem. Commun. 2012, 48, 711713.

(43) Liu, Y. L.; Tseng, M. C.; Fangchiang, M. H. Polymerization and nanocomposites properties of multifunctional methylmethacrylate POSS. J. Polym. Sci., Part A: Polym. Chem. 2008, 46, 5157-5166.

(44) Zhang, W.; Jing, Z.; Shan, Y.; Ge, X.; Mu, X.; Jiang, Y.; Li, H.; $\mathrm{Wu}, \mathrm{P}$. Paper reinforced with regenerated cellulose: a sustainable and fascinating material with good mechanical performance, barrier properties and shape retention in water. J. Mater. Chem. A 2016, 4, $17483-17490$.

(45) Pramudya, I.; Rico, C. G.; Lee, C.; Chung, H. POSS-containing bioinspired adhesives with enhanced mechanical and optical properties for biomedical applications. Biomacromolecules 2016, 17, 3853-3861.

(46) Bras, M. L.; Wilkie, C. A.; Bourbigot, S. Octaisobutyl POSS Thermal Degradation. In Fire Retardancy of Polymers: New Applications of Mineral Fillers; RSC, 2005; pp 1-125. 